\title{
Redox Heterogeneity Entangles Soil and Climate Interactions
}

\author{
Jared L. Wilmoth
}

check for

updates

Citation: Wilmoth, J.L. Redox Heterogeneity Entangles Soil and Climate Interactions. Sustainability 2021, 13, 10084. https://doi.org/ $10.3390 /$ su131810084

Academic Editors: Raymond R. Weil and Tessa Sophia van der Voort

Received: 28 July 2021

Accepted: 7 September 2021

Published: 9 September 2021

Publisher's Note: MDPI stays neutral with regard to jurisdictional claims in published maps and institutional affiliations.

Copyright: (C) 2021 by the author. Licensee MDPI, Basel, Switzerland. This article is an open access article distributed under the terms and conditions of the Creative Commons Attribution (CC BY) license (https:/ / creativecommons.org/licenses/by/ $4.0 /)$.
Department of Environmental Science and Technology, University of Maryland, College Park, MD 20742, USA; jwilmoth@umd.edu; Tel.: +1-301-405-1306

\begin{abstract}
Interactions between soils and climate impact wider environmental sustainability. Soil heterogeneity intricately regulates these interactions over short spatiotemporal scales and therefore needs to be more finely examined. This paper examines how redox heterogeneity at the level of minerals, microbial cells, organic matter, and the rhizosphere entangles biogeochemical cycles in soil with climate change. Redox heterogeneity is used to develop a conceptual framework that encompasses soil microsites (anaerobic and aerobic) and cryptic biogeochemical cycling, helping to explain poorly understood processes such as methanogenesis in oxygenated soils. This framework is further shown to disentangle global carbon $(\mathrm{C})$ and nitrogen $(\mathrm{N})$ pathways that include $\mathrm{CO}_{2}, \mathrm{CH}_{4}$, and $\mathrm{N}_{2} \mathrm{O}$. Climate-driven redox perturbations are discussed using wetlands and tropical forests as model systems. Powerful analytical methods are proposed to be combined and used more extensively to study coupled abiotic and biotic reactions that are affected by redox heterogeneity. A core view is that emerging and future research will benefit substantially from developing multifaceted analyses of redox heterogeneity over short spatiotemporal scales in soil. Taking a leap in our understanding of soil and climate interactions and their evolving influence on environmental sustainability then depends on greater collaborative efforts to comprehensively investigate redox heterogeneity spanning the domain of microscopic soil interfaces.
\end{abstract}

Keywords: soil redox; heterogeneity; climate feedback; soil carbon (C); soil nitrogen (N); soil microsites; cryptic biogeochemical cycling; methane $\left(\mathrm{CH}_{4}\right)$ paradox; wetlands; tropical forests

\section{Introduction}

Determining the vulnerability of both current and potentially sustainable systems to climate change depends on our knowledge of how soils, collectively forming the reactive terrestrial surface and extending to the subsurface and sediments of the Earth, function at microscopic, biogeochemical, interfaces. To gain a deeper understanding of these interfaces and how they link to climate change, new conceptual frameworks that center on universal parameters need to be developed to adequately describe the complex interactions that exist between the surfaces of minerals, microbial cells, soil organic matter, and plant tissues in different environments on a global scale. Soil redox status is essentially a universal parameter and a well-recognized master variable that can be used to broadly describe and predict biogeochemical processes. However, soil redox conditions are remarkably dynamic depending on the system, displaying heterogeneity over different spatiotemporal scales, which are only beginning to be fully acknowledged and thoroughly evaluated in the face of climate change [1-4].

Aggregate-scale redox heterogeneity is likely to be more ubiquitous in soils than previously thought and can potentially signal dramatic changes in soil $\mathrm{C}$ stabilization and mineralization [3,5-8]. Research on cryptic biogeochemical cycling offers further insight into how coupled abiotic and biotic reactions might transmit rapid $C$ and climate feedback across redox-heterogeneous zones $[2,4,9]$. The $\mathrm{C}$ and $\mathrm{N}$ cycles, including greenhouse gas emissions (i.e., $\mathrm{CO}_{2}, \mathrm{CH}_{4}$, and $\mathrm{N}_{2} \mathrm{O}$ ), are intricately tied to the biogeochemical cycling of iron (Fe) in many soils [2,10]. Rapid electron transfer between $\mathrm{C}, \mathrm{Fe}$, and $\mathrm{N}$ species is regulated by geochemical and microbial reactions, which are in turn affected by redox 
heterogeneity [2]. Identifying the critical redox couples and intermediates within each reaction pathway is exceedingly difficult, especially if they traverse shifting redox regimes and rapidly transform [4]. This further complicates the identification of mechanisms that underpin soil and climate interactions, ultimately obscuring the connections between soil redox heterogeneity and large-scale phenomena such as climate change. An important example of this involves $\mathrm{CH}_{4}$ emissions from oxygenated soils [11-15]. Emerging data indicate that methanogenesis in soils is not constrained to the deepest, inundated, and most anaerobic/anoxic layers as has been the paradigm in soil and climate research $[11,13,14]$. A growing body of evidence indicates that $\mathrm{CH}_{4}$ production significantly, perhaps even ubiquitously, occurs in near-surface oxygenated soils in different ecosystems ranging from wetlands to humid tropical forests $[3,11,13,15,16]$.

A common feature shared by aggregate-scale microsites, cryptic biogeochemical cycling, and $\mathrm{CH}_{4}$ production in oxygenated soils is that they all appear to be regulated by redox heterogeneity operating over short spatiotemporal scales. Whether redox heterogeneity takes the form of a distinct transition, gradient, or oscillation in local redox conditions, most soils experience redox heterogeneity as multidirectional oxidizing-to-reducing and /or aerobic-to-anaerobic (including facultative) boundary conditions over different spatiotemporal scales. These boundary conditions can overlap on very short spatiotemporal scales in soils and allow for various biogeochemical feedback mechanisms and sectoring of the soil microbiome, setting the stage for a tapestry of redox transition zones with major consequences on nutrient availability and greenhouse gas emissions $[1,2,17]$.

As the research scope widens, it is becoming clear that our understanding of soil and climate interactions requires a more fundamental and multidimensional conceptualization of redox heterogeneity in soils based on microscopic soil interfaces and shorter spatiotemporal scales. Climate change in the form of altered precipitation patterns, wet-dry cycling, soil warming, sea-level rise, storm surges, coastal flooding, altered wind dynamics, and more frequent and intense forest fires could drive extreme changes in soil redox conditions. Greenhouse gas emissions from soil in turn drive climate change and are regulated by redox heterogeneity. The present paper examines the ways in which soil redox heterogeneity fundamentally and intricately regulates soil and climate interactions. Once it is more fundamentally conceptualized, redox heterogeneity can be used to explain and unravel the entangled nature of these interactions.

\section{Redox Heterogeneity over Short Spatiotemporal Scales in Soil}

How does redox heterogeneity at the level of minerals, microbial cells, organic matter, and the rhizosphere entangle biogeochemical cycles with climate change? This is a profound question considering that soil redox conditions regulate global $\mathrm{C}$ cycling and that soils are described as both the largest terrestrial reservoir and the largest dynamic stock of $C$ on Earth [3,7]. Importantly, a general answer to this question is needed to help explain fine-scale environmental processes (e.g., involving $\mathrm{C}$ and $\mathrm{N}$ transformations) that are linked to climate change. Complex, fine-scale, processes such as anaerobic and aerobic microsite formation, cryptic biogeochemical cycling, and $\mathrm{CH}_{4}$ emissions from oxygenated soils share common mechanistic features that arise from redox heterogeneity operating over short spatiotemporal scales in soil (Figure 1). 


\section{Climate}

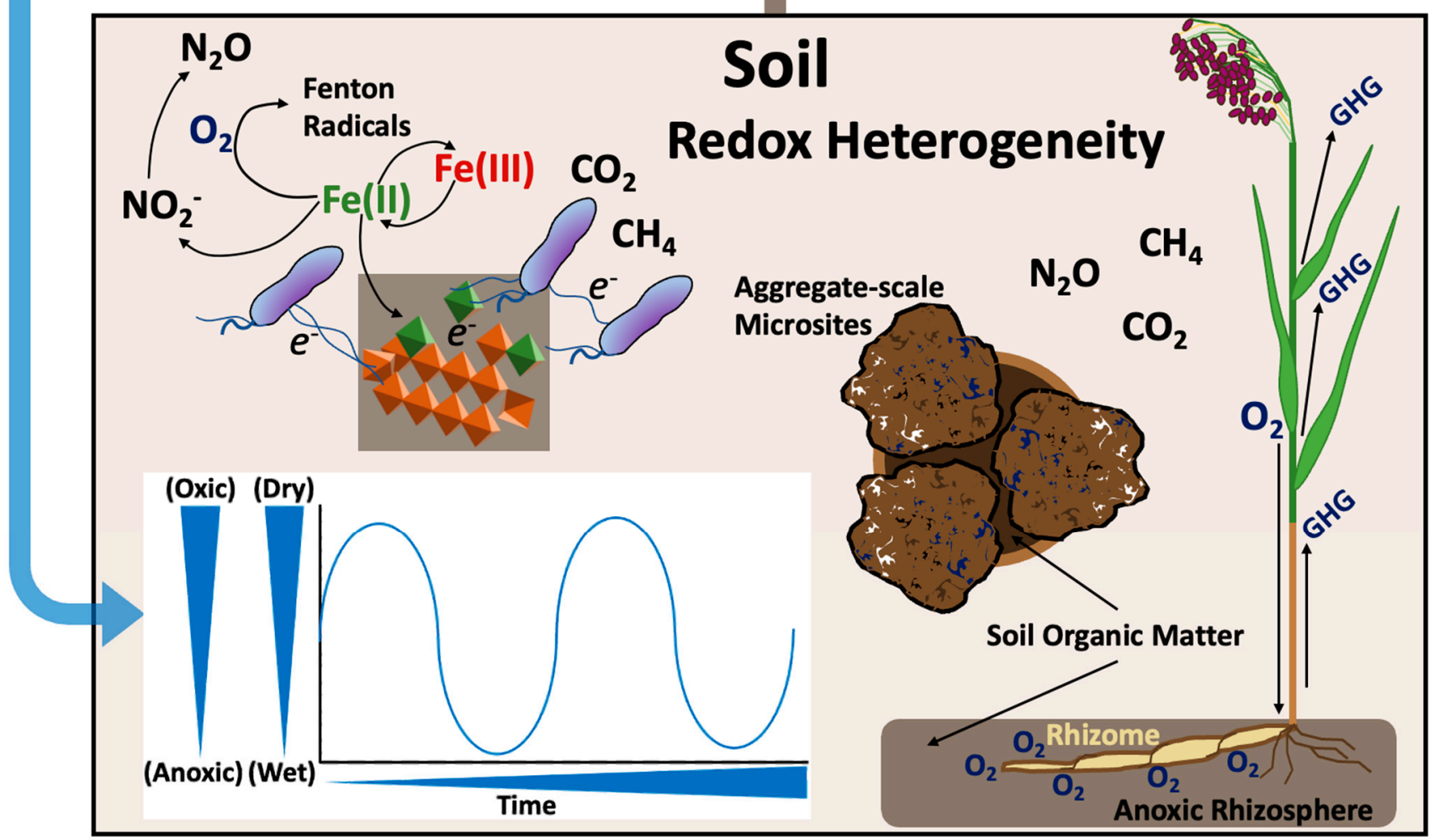

Figure 1. Conceptual framework of fine-scale redox heterogeneity in soils. The framework illustrates redox heterogeneity spanning mineral, microbial, organic, aggregate, and wetland-rhizosphere interfaces. Greenhouse gases $\left(\mathrm{CH}_{4}, \mathrm{CO}_{2}, \mathrm{~N}_{2} \mathrm{O}\right.$, GHGs) are shown in different pathways. The blue oscillation graph in the lower left corner indicates soil conditions that vary with time and correlate with redox heterogeneity relevant to all the scenarios shown in the main figure. The large brown and blue arrows revolving in the upper left corner indicate soil and climate interactions. Between the head of the blue arrow and the tail of the brown arrow, these interactions are entangled by redox heterogeneity. The mineral, microbial, organic, aggregate, and wetland-rhizosphere features, as well as the oscillating conditions, can be envisioned to coexist in different environmental systems discussed in the main text and are not meant to be mutually exclusive in this framework. Additionally, though not explicitly shown, other organisms such as earthworms and various soil mesofauna collectively form an integral part of this conceptual framework, especially because they transfer and transform soil organic matter, influence aggregate structure, degrade plant tissues, and open physical channels for nutrient and gas exchange among the different soil interfaces.

Redox heterogeneity is expected to direct the interactions between minerals, microbial cells, and organic matter within and between soil microsites. Aggregate-scale microsites are often comprised of clay minerals and $\mathrm{Fe}$ and $\mathrm{Al}$ (oxyhydr)oxides that can protect (i.e., stabilize) soil organic matter from microbial access (i.e., physical or enzymatic), making mineral-associated $\mathrm{C}$ and $\mathrm{N}$ less bioavailable for microbial metabolic processing [3]. However, changes in soil structure and moisture can lead to heterogeneous redox conditions, and as redox conditions shift over short spatiotemporal scales within or between soil aggregates, the microbial bioavailability of $\mathrm{C}$ and $\mathrm{N}$ also changes [7]. Redox heterogeneity involving the flow of electrons between $\mathrm{C}, \mathrm{Fe}, \mathrm{N}$, and $\mathrm{O}_{2}$ spans mineral-microbial interfaces, where these interfaces can be further envisioned to exist in the microsites of soil aggregates (Figure 1). For example, anaerobic microsites develop in otherwise oxygenated soils when aggregate pore spaces become saturated with water and the pore-space $\mathrm{O}_{2}$ is quickly consumed during aerobic respiration $[3,5,7]$. When $\mathrm{O}_{2}$ becomes sufficiently depleted as a terminal electron acceptor, subsequent hypoxic/anoxic conditions set in and the rate of organic $C$ degradation may decrease under anaerobic conditions. Current research indicates that anaerobic, aggregate/pore-scale, microsites in upland (i.e., qualitatively bulk 
dry, oxygenated, well drained) soils need to be considered more often when modeling greenhouse gas emissions from soils on a global scale $[3,6,7,18]$. These microsites are conceptually delineated based on attributes such as pore-size distribution, physical compaction and degradation (relevant to agricultural systems), and moisture and $\mathrm{O}_{2}$ gradients within, or between, soil aggregates [7]. The results suggest that anaerobic microsites can stabilize soil C, at least temporarily, until oxygenation (i.e., aeration) diminishes anaerobic metabolic pathways and initiates aerobic respiration that increases the production of $\mathrm{CO}_{2}$. Anaerobic microsites have gained recognition as protected, albeit dynamic, stocks of soil organic matter in otherwise oxic soil environments. Still, spatiotemporal partitioning of oxic (aerobic) and anoxic (anaerobic) microsites is poorly understood at the aggregate scale in most environments, especially regarding how neighboring microsites might be bridged by coupled aerobic and anaerobic pathways spanning local redox transitions. Aerobic microsites in otherwise hypoxic/anoxic soil environments, such as wetlands, are extremely important to consider in this context $[19,20]$. The biogeochemical cycling of $\mathrm{C}$ and $\mathrm{N}$ in wetland soils is tightly regulated by the presence and distribution of $\mathrm{O}_{2}$ in the rhizosphere. Wetland soils often develop thick organic-rich layers from decomposing plant biomass that can lack distinct aggregate structure in their profile compared to clay-rich upland soils. Many wetland plants survive extremely wet or flooded conditions via transport of $\mathrm{O}_{2}$ down to their root and rhizome networks (e.g., through aerenchyma tissues mediated by factors such as solar energy, internal humidity gradients, and external wind dynamics) for maintaining below-ground plant cellular respiration during inundation by water. Transport of $\mathrm{O}_{2}$ down to the roots and rhizomes can establish transient aerobic microsites in the surrounding anaerobic/anoxic rhizosphere, leading to redox heterogeneity over short spatiotemporal scales $[19,21,22]$.

The above comparison between uplands and wetlands illustrates that the redox heterogeneity of microsites is a more fundamental, universal, property of soils that does not strictly arise from soil aggregates or soil structure. Plant-transported $\mathrm{O}_{2}$ to wetland rhizospheres does not necessarily depend on aggregate-like soil structure, but on the root-rhizome-soil interface. Even within clay-rich soil aggregates in uplands, redox heterogeneity at mineral-microbial interfaces does not strictly depend on soil structure. More fundamentally, soil microsite conditions can be conceptualized to arise wherever, or whenever, redox heterogeneity spans the domain of mineral, microbial, organic matter and rhizosphere interfaces (Figure 1). At this level, redox heterogeneity is defined by the flow of electrons between microscopic interfaces and intermediate redox couples, the lifetime of which is extremely important for measuring and tracking abiotic and biotic reactions.

Cryptic biogeochemical cycling involves the rapid transformation of, or rapid transfer of electrons between, short-lived abiotic and biotic intermediates in different environments $[2,4,9]$. Cryptic cycling is an important feature of soils affected by fine-scale redox heterogeneity. One example of cryptic Fe cycling relevant to soil and climate interactions, especially in environments impacted by agricultural fertilizer additions, is the microbial reduction of $\mathrm{NO}_{3}{ }^{-}$and the subsequent abiotic reduction of $\mathrm{NO}_{2}{ }^{-}$with $\mathrm{Fe}$ (II) (as electron donor in both processes) to form $\mathrm{N}_{2} \mathrm{O}$ [1,23-25] (Figure 1). This cryptic cycle could be envisioned to exist within soil aggregates or between neighboring microsites, for example, using the redox heterogeneity framework presented in Figure 1. The cryptic, Fe(II)-driven, pathway of $\mathrm{Fe}$ and $\mathrm{N}$ overlaps with microbial nitrification/denitrification that forms biogenic (biotic) $\mathrm{N}_{2} \mathrm{O}$. Overlap in cryptic cycles also involves soil $C[2,26]$. In this example with $\mathrm{Fe}$ and $\mathrm{N}, \mathrm{Fe}(\mathrm{III})$-reducing bacteria can oxidize and transfer electrons from organic C to solid-phase Fe(III), reducing this Fe(III) to Fe(II), and whether this newly formed $\mathrm{Fe}(\mathrm{II})$ remains associated (e.g., sorbed) with the solid phase or becomes solubilized, it may then proceed to abiotically react with $\mathrm{NO}_{3}{ }^{-}$to form $\mathrm{NH}_{4}{ }^{+}[1,27]$ and/or $\mathrm{NO}_{2}{ }^{-}$to form $\mathrm{N}_{2} \mathrm{O}$ [23,24]. During abiotic or biotic (e.g., with Fe(II)-oxidizing bacteria) oxidation events, some of the remaining Fe(II) could be converted back to solid-phase Fe(III), or some $\mathrm{Fe}(\mathrm{II})$ may function as a catalyst in Fenton-like reactions to generate oxidative radicals that further break down organic C [28]. Redox heterogeneity over short spatiotemporal scales, 
such as mineral-microbial interfacial scales, can intricately regulate cryptic cycling in soils (Figure 1).

Redox heterogeneity exists even at the cellular level of individual microbes in the environment. Certain anaerobic bacteria in anoxic sediments have been shown to couple the oxidation of $\mathrm{CH}_{4}$ to the reduction of $\mathrm{NO}_{2}{ }^{-}$by uniquely producing their own $\mathrm{O}_{2}$ from nitric oxide (NO), then using this $\mathrm{O}_{2}$ to oxidize $\mathrm{CH}_{4}$ to $\mathrm{CO}_{2}$ under anaerobic/anoxic conditions [29]. Anaerobes can also use external or self-produced electron-shuttling compounds to catalyze extracellular reduction of terminal electron acceptors (e.g., Fe(III)) [2,30,31]. Further, anaerobic microbial biofilms can form on mineral surfaces, allowing for unique process such as nanowire and interspecies electron transfer [32-34] (Figure 1). Iron(III)-reducing bacteria can transfer electrons extracellularly to solid-phase Fe(III) or to methanogens to syntrophically produce $\mathrm{CH}_{4}[16,32,34]$. Different microbial sectors in the microbiome can partition or display structured assembly due to spatial confinement, even displaying aggregate-like characteristics that do not require soil minerals [17,35]. Similarly, nanoparticles such as those of Fe-(oxyhydr)oxides can assemble with each other, including assemblages with microbial cells and soil organic matter, and may have mixed valency (i.e., containing $\mathrm{Fe}(\mathrm{III})$ and $\mathrm{Fe}(\mathrm{II})$ ), where redox heterogeneity spans the micro- and nano-size ranges $[8,16,26,33,36,37]$.

These processes demonstrate how soil and climate interactions, involving the global cycling of $\mathrm{C}$ and $\mathrm{N}$ between soils and the atmosphere, are entangled by fine-scale redox heterogeneity in soils. Redox heterogeneity is central to the conceptual framework discussed and developed in this section (Figure 1). Importantly, this framework can be broadly applied to better study microsites and cryptic biogeochemical cycling in soils. In the next section, the application of this conceptual framework will be demonstrated to help unravel the paradox of $\mathrm{CH}_{4}$ emissions from oxygenated soils.

\section{Applying Redox Heterogeneity to Disentangle the Soil $\mathrm{CH}_{4}$ Paradox}

Historically, $\mathrm{CH}_{4}$ emissions from soils have been viewed to originate primarily from deep, inundated, strictly anoxic, layers [14]. This view stems from the fact that methanogenesis is generally recognized to be a strictly anaerobic process. More recently, methanogenesis in oxygenated soils has been reported to occur in ecosystems ranging from wetlands [11-13] to humid tropical forests [15,16,38], where near-surface oxygenated soil can account for up to $90 \%$ of total $\mathrm{CH}_{4}$ emissions from certain wetlands [11]. The mechanisms of this process in soil appear to be unique, at least when compared to $\mathrm{CH}_{4}$ emissions from oxygenated marine waters where $\mathrm{CH}_{4}$ can be generated during the aerobic degradation of dissolved organic, methylated, phosphonates [39]. In the case of soils, studies suggest that anaerobic microsites might facilitate $\mathrm{CH}_{4}$ emissions in otherwise oxygenated environments $[3,11,14]$. However, it is not clear how $\mathrm{CH}_{4}$ production, a putative anoxic process, is significantly increased by the presence of $\mathrm{O}_{2}$ in soils. If instead we apply the concept of redox heterogeneity more fundamentally, as described in the last section, we could envision a scenario where methanogens benefit from local and/or transient oxygenation to fuel the production of $\mathrm{CH}_{4}$ (Figure 2). 


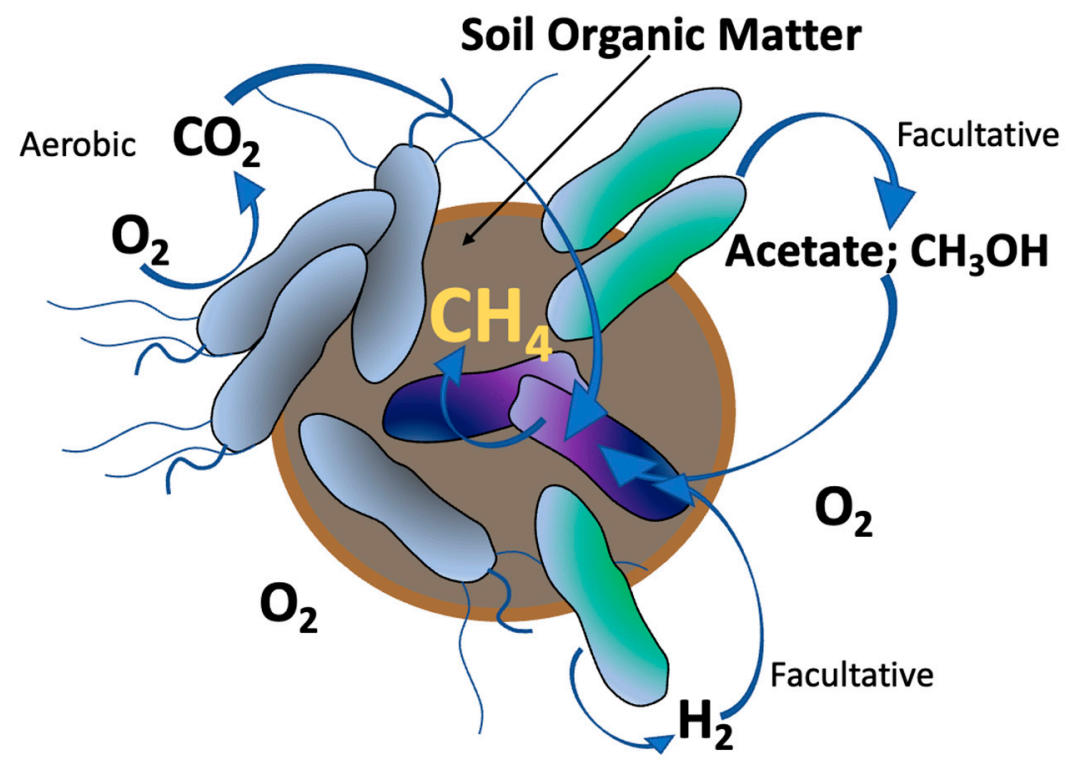

Figure 2. Methanogenic (purple cells), aerobic (grey cells), and facultative (green cells) microbial pathways are envisioned to overlap on short spatiotemporal scales to allow for methanogenesis in oxygenated soils. This follows from concepts in Figure 1 that are further discussed in the main text of Section 3. Although other microbial cells are shown here to surround the methanogen cells, there is no requirement that methanogens be physically shielded from $\mathrm{O}_{2}$. The only requirement is that $\mathrm{O}_{2}$ is a short-lived redox intermediate, irrespective of any spatial or physical constraints. In this way, $\mathrm{O}_{2}$ can indirectly fuel methanogenic activity by increasing the activity and/or biomass of local aerobic and facultative microbes to produce more methanogenic substrates, and thus increase $\mathrm{CH}_{4}$ emissions from oxygenated soils.

Recent data suggest that methanogens are resilient to oxygenation in soil, even when aggregate structure is not present, such as in incubated soil suspensions $[12,16]$. It is possible that aerobes and facultative microbes, in close proximity to the methanogens, quickly convert $\mathrm{O}_{2}$ to $\mathrm{CO}_{2}$, where this produced $\mathrm{CO}_{2}$ can then be rapidly used as a substrate for methanogenesis (Figure 2). This pathway would also involve the transient production and consumption of $\mathrm{H}_{2}$, acetate, and $\mathrm{C}-1$ compounds to produce $\mathrm{CH}_{4}$. In this scenario, redox heterogeneity spanning aerobic, facultative, and anaerobic microbial interfaces would help explain how soil oxygenation could cryptically fuel methanogenesis without invoking soil aggregate structure (i.e., as a critical microsite characteristic). Accordingly, we only need to consider redox heterogeneity spanning microbial cells, regardless of distinct structural features of soil (e.g., aggregates or pore spaces). Within the framework of finescale redox heterogeneity (Figures 1 and 2), there is no rule specifying that methanogens and aerobes, or facultative microbes, cannot come into close spatiotemporal proximity with each other or metabolically overlap. Over short spatiotemporal scales, redox intermediates (e.g., $\mathrm{O}_{2}, \mathrm{CO}_{2}, \mathrm{CH}_{4}$, organic matter, etc.) could simply become part of the cryptic metabolic pipeline between aerobic, facultative, and anaerobic microbes (Figure 2). This connection is often overlooked in large-scale system models that divide soils into broader aerobic (or oxic) and anaerobic (or anoxic) areas, which include soil layers, soil depths, and even soil aggregates. However, at the level of minerals, microbial cells, organic matter, and the rhizosphere, such generalized, coarse, delineation can lead to overlooking the nuances of soil and climate interactions and global $\mathrm{CH}_{4}$ emissions from soils. This is an important point for climate models and simulations because climate-driven perturbations could dramatically alter these fine-scale redox processes.

\section{Climate-Driven Redox Perturbations in Soil}

Climate change has the potential to cause various redox perturbations in soils worldwide depending on the ecosystem. These climate-driven perturbations could significantly 
alter the fine-scale properties of redox heterogeneity in soils and increase the emissions of greenhouse gases to the atmosphere (Figure 3). Broader biogeochemical cycles, anthropogenic practices, and inevitably environmental sustainability would all be influenced in critical ways.

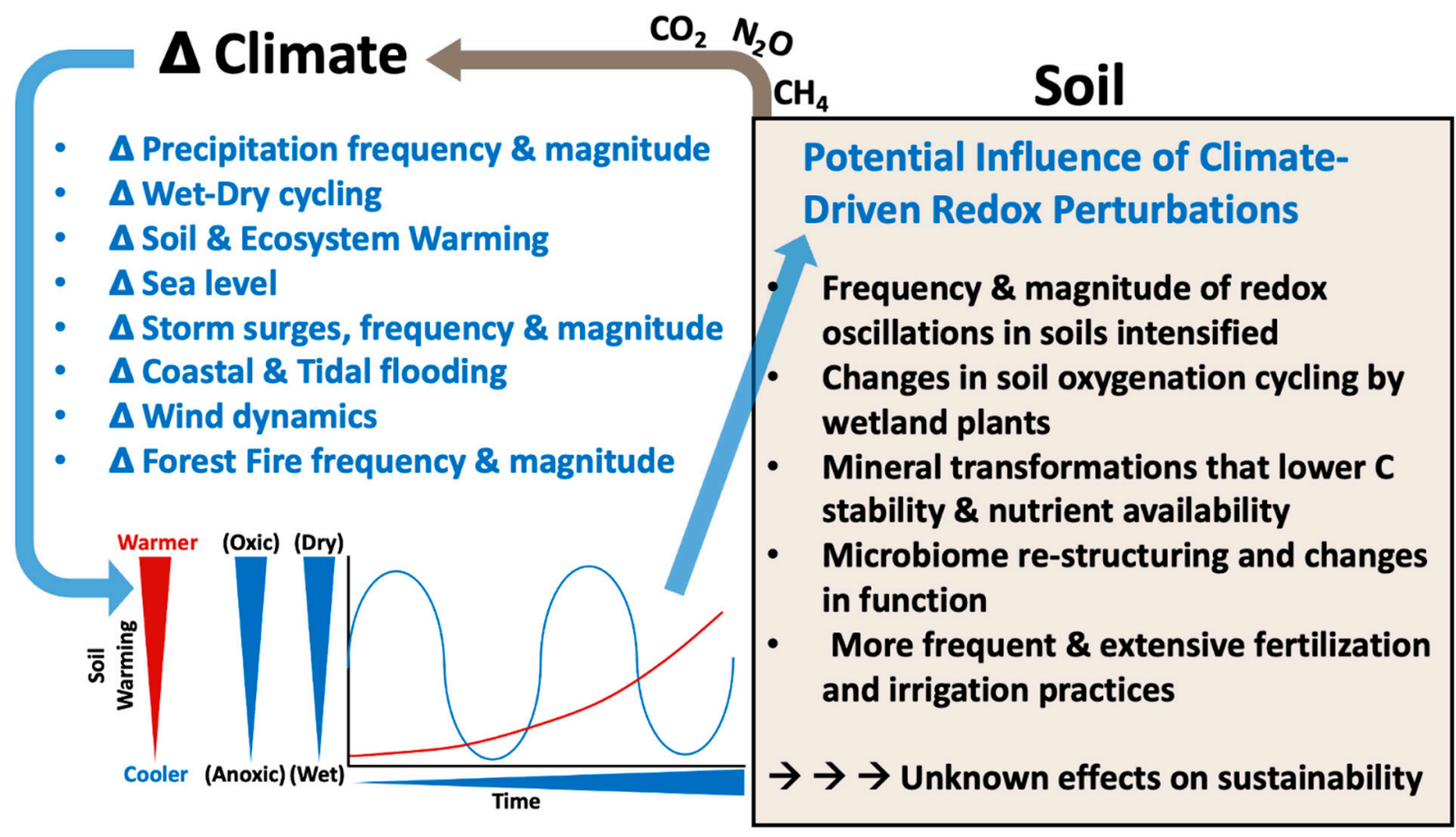

Figure 3. Climate change, in various forms, is shown to cause redox perturbations in soil. These climate-driven redox perturbations are linked to GHG emissions and multiple biogeochemical processes in different ecosystems, where they can regulate soil redox conditions over short spatiotemporal scales, as well as bulk redox conditions over larger areas of the landscape.

Wetlands ranging from coastal to inland areas represent unique ecosystems that allow for the monitoring of climate-driven redox perturbations in real time on a global scale [22]. In tidal wetlands, these redox perturbations involve the dynamics of cyclical flooding, including wetting and drying cycles [19]. Whether through changes in sea level or changes in the frequency and magnitude of storm surges [20], climate change can alter these dynamics and therefore alter redox heterogeneity in these soils. Any fine-scale change to redox heterogeneity in soils forced by climate-driven redox perturbations will almost certainly display sensitive feedback with $\mathrm{C}$ and $\mathrm{N}$ cycling $[3,40]$. If these perturbations result in higher $\mathrm{CO}_{2}, \mathrm{CH}_{4}$, and $\mathrm{N}_{2} \mathrm{O}$ emissions from coastal wetlands, then a positive soil and climate feedback will be triggered and could further escalate with advancing climate change [13,14,20,22,41] (Figure 3). Extensive wetland networks further inland (e.g., the Prairie Pothole Region spanning the USA and Canada) may not be immediately affected by sea-level rise or coastal storm surges, but local changes in precipitation and wet-dry cycling brought on by climate change could similarly alter soil redox heterogeneity and soil and climate interactions [42]. In common to both coastal and inland wetlands, as mentioned previously, many wetland plants use solar energy and internal humidity gradients, among other physiological mechanisms, to transport $\mathrm{O}_{2}$ down to their root and rhizome networks [19-22]. Below-ground plant tissue concentrations of $\mathrm{O}_{2}$ have been shown to peak during the day and sharply drop during the night, and so this pattern of oxygenation can repeat on a diurnal cycle within the otherwise hypoxic/anoxic rhizosphere, where the radial loss (i.e., outward diffusion or leaking) of $\mathrm{O}_{2}$ from rhizome tissues is expected [19]. In some coastal wetlands, these diurnal oxygenation cycles might also partially overlap with the cycling of tidal waters [20]. This compounded diurnal oxygenation cycling by wetland 
plants and tidal cycling, influencing fine-scale redox heterogeneity in soils, represents a unique superposition of spatiotemporal redox oscillations. Climate change, therefore, has the potential to affect $\mathrm{O}_{2}$ transport to the rhizosphere of wetland plants in different geographic areas in complex ways, perhaps through increased ambient and/or soil warming to cause internal plant transport-gradient stresses, in addition to the impact of climate change on precipitation and flooding characteristics. This also includes any effects on greenhouse gas transport through plant tissues from soils to the atmosphere, where vegetation such as common reeds and large trees can facilitate this transport in wetlands [22,43]. Although wetlands serve as extensive biogeochemical and ecological indicators to monitor climate change, they are also important for modeling environmental sustainability. For example, wetlands are used as buffer zones between urban and coastal systems. Wetland plants are actively being studied as biofuel stocks, are commonly used to mitigate the harmful effects of industrial pollution, and are used to stabilize sediments and prevent erosion, and some wetland plants also serve as a food source for humans and livestock, as well as provide a vital refuge for wildlife [22,44].

Tropical forest soils, like wetland soils, exist within unique ecosystems that are influenced by climate-driven redox perturbations $[16,40]$. Depending on the geographic location, these redox perturbations may be intensified due to changes in forest warming, the frequency and intensity of forest fires that can alter $\mathrm{C}$ biogeochemistry and the microbiome, hurricane magnitude and frequency, and altered precipitation patterns and wet-dry cycling [40,45] (Figure 3). Tropical forest soils (e.g., soils of the Luquillo Critical Zone Observatory (LCZO), Puerto Rico) display high turnover rates of soil organic C that are linked to soil-redox oscillations [40]. Precipitation and wet-dry cycling establish redox-oscillating conditions that can change rapidly on a day-to-day basis and by soil depth, where the $\mathrm{O}_{2}$ levels can shift between $0 \%$ and atmospheric concentration [46-48]. Organic $C$ inputs to the soil are supplied by leaf litter from the overlying tree canopy and abundant Fe-(oxyhydr)oxides in the soil have an important role in stabilizing soil C [40]. Aerobic and anaerobic respiration are both equally high, owing in part to the constant input of organic C and the abundance of solid-phase Fe(III) as a terminal electron acceptor under low oxygenation [41,46,47]. Crystal order and reactivity of the Fe-(oxyhydr)oxides are significantly altered by soil redox oscillations, which further regulate $C$ and nutrient cycling [16,28,49-51]. For example, organic C forms co-precipitated complexes with Fe(oxyhydr)oxides, where phosphorus (P) also strongly sorbs to Fe-(oxyhydr)oxides, and so $\mathrm{Fe}(\mathrm{III})$-reducing bacteria can significantly impact the coupled C-Fe-P cycle during redox oscillations and dissimilatory Fe(III) reduction $[30,41,52,53]$. The microbiome of tropical soils has been shown to quickly respond to different redox-oscillating conditions and there are many biogeochemical pathways that may be hypothesized to shift due to climatedriven redox perturbations now and in the immediate future $[16,38,46]$. For instance, $\mathrm{CH}_{4}$ production and high methanogenic activity have been observed in tropical soils in the field and when incubated under different levels of headspace $\mathrm{O}_{2}$ in the laboratory $[15,16]$, which is important because soil aeration in the field is sensitive to the effects of climate change. These results are relevant to the soil $\mathrm{CH}_{4}$ paradox discussed in the last section. Methanogens have been indicated to primarily use the $\mathrm{H}_{2} / \mathrm{CO}_{2}$ (i.e., hydrogenotrophic) pathway to produce $\mathrm{CH}_{4}$ during short redox oscillations in the laboratory [16], which is important because $\mathrm{H}_{2}$ is also an electron donor for Fe(III)-reducing bacteria during the reduction of $\mathrm{Fe}(\mathrm{III})$, and $\mathrm{CO}_{2}$ is readily produced under both aerobic and anaerobic conditions during redox oscillations. Interspecies electron transfer from Fe(III)-reducing bacteria to methanogens could also be important, because class (III) signal peptide gene expression of methanogens has been implicated in a type-IV pili assembly mechanism during Fe(III)-reducing conditions in tropical soils linked to redox oscillations [16,32]. Climate-driven redox perturbations are therefore expected to alter this overall Fe and C cycling in tropical forest soils on a global scale.

Wetlands and tropical forests help to monitor, model, and predict the impact of climate-driven redox perturbations in soils and on environmental sustainability worldwide. 
Information from these ecosystems can be extended to other more specific environments to assess the potential local impacts of climate change. For example, different wetlands that support rice cultivation are vulnerable to climate-driven redox perturbations, as well as highly weathered agricultural soils in Africa, China, and India that receive abundant fertilizer inputs and are replete with Fe minerals [54-58]. Furthermore, climate change could cause wider irrigation practices to adapt in such a way as to influence soil redox perturbations in local areas (Figure 3). These considerations show the great importance of studying climate-driven redox perturbations in various soils, in addition to understanding the general impact of climate change on agricultural practices such as the additions of $C$ and $\mathrm{N}$, and water management strategies related to the frequency and magnitude of irrigation.

\section{Multifaceted Analysis of Redox Heterogeneity in Soils}

Throughout the preceding sections, a conceptual framework has been developed which shows how redox heterogeneity operates in soils to intricately regulate soil and climate interactions (Figures 1 and 2), including how redox heterogeneity in turn can be influenced by climate-driven redox perturbations (Figure 3). This multifaceted soil and climate feedback requires an equally multifaceted analytical approach to gain deeper insight into the underlying biogeochemical mechanisms. Although an extensive, detailed, list of relevant analytical techniques is beyond the scope of the present paper, there are specific powerful techniques that could be used in more combined formats for future research. This section will focus on the unique capabilities of (1) molecular omics, (2) Fourier transform ion cyclotron resonance mass spectrometry (FT-ICR-MS) and Orbitrap mass spectrometry (MS), (3) synchrotron X-ray absorption spectroscopy (XAS), (4) microfluidics, and high-performance computing using (5) agent-based modeling and (6) molecular dynamics simulations to help guide the development of comprehensive, combined, analytical approaches (Figure 4).

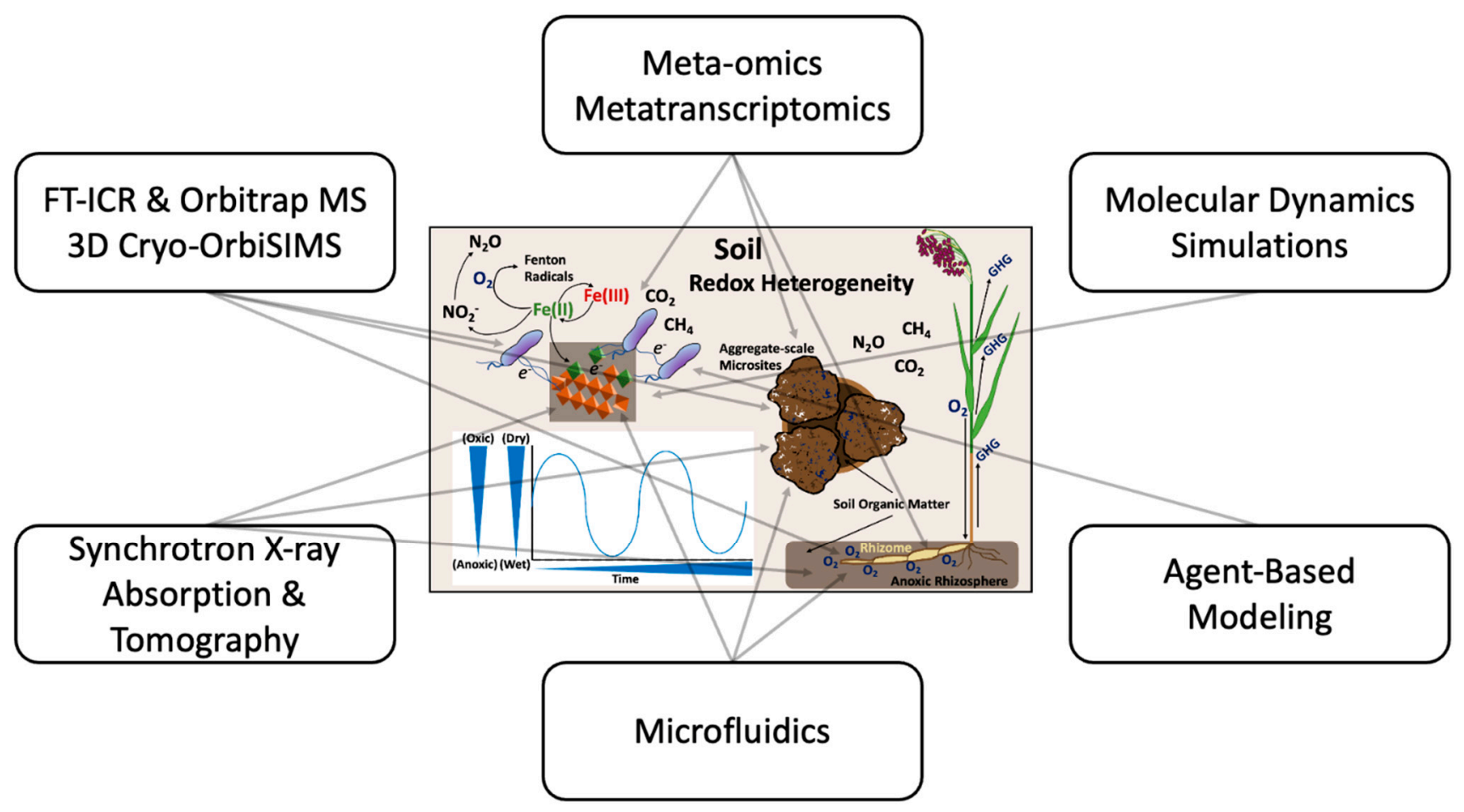

Figure 4. Meta-omics, Fourier transform MS, synchrotron, microfluidics, agent-based modeling (ABM), and molecular dynamics (MD) simulations are matched to common features of redox heterogeneity in soil, indicating the potential for combined analyses in future research. This figure emphasizes the importance of using multiple analytical techniques for a more comprehensive characterization of redox heterogeneity operating over short spatiotemporal scales in soils. 
(1) Molecular omics analyses, such as metagenomics (i.e., soil DNA and metagenomeassembled genomes), metatranscriptomics (i.e., soil mRNA and broad gene expression analysis), proteomics, metabolomics, etc., have gained wide use and development in recent years for soils research [11,16,32,56,59]. Metatranscriptomics offers a wide characterization, over short time scales, of the active microbial populations in soil and which biogeochemical processes they are actively mediating [16]. Importantly, metatranscriptomics can reveal the biological pathways used to direct redox reactions that involve various abiotic and biotic reactions in soils [16,32]. (2) Fourier transform mass spectrometers have an extremely high mass-resolving power and mass accuracy compared to other MS techniques [60,61]. Ultrahigh-resolution mass spectrometry, such as FT-ICR-MS and Orbitrap-MS, allows for the simultaneous analysis of hundreds to thousands of different organic molecules from soil-derived water and chemical extracts based on exact $m / z$ ratios $[3,28,62,63]$. Both techniques allow for the prediction and classification of molecular formulae in unknown samples, and are both sensitive to isotopic composition (e.g., these techniques can be used for stable isotope probing (SIP) experiments) [28]. These techniques can also be used to calculate the nominal oxidation state of C (NOSC) for individual organic compounds, where a low NOSC value corresponds to a more reduced species and a higher NOSC value corresponds to a more oxidized species. The NOSC value of an organic molecule can further be used to calculate the free energy of a reaction involving the oxidation of that molecule by different electron acceptors (e.g., $\mathrm{O}_{2}$ or $\mathrm{Fe}(\mathrm{III})$ ) [3]. FT-ICR-MS and Orbitrap-MS have both recently been coupled to secondary ion MS (SIMS), paving the way for high spatial resolution analyses (i.e., chemical mapping) that can characterize a broad range of inorganic and organic interfaces $[60,64]$, potentially including the redox-relevant NOSC values for detected organic molecules [3], which is highly important for studying soil samples where different biogeochemical interfaces and redox conditions are present [28]. A 3D CryoOrbiSIMS technique has very recently been used to generate 3D chemical maps of bacterial biofilms in their native state [64], which likely has great potential to be developed further for future soils research, especially if NOSC values can be obtained for the detected organic molecules. Characterization of soils using SIMS, including NanoSIMS [65], allows chemical maps to be generated ranging from the nano- to micro-scale. The SIMS techniques are also able to measure differences in isotopic composition. Depending on the ion beam(s) used to characterize a sample, individual elements and small to large molecules, including large biomolecules, can be measured by SIMS. It should be noted that some of these more advanced MS techniques are being used in only a relatively small number of labs worldwide, however, they are overall becoming more available for environmental studies. (3) Synchrotron XAS, including XANES and EXAFS, allows for the chemical mapping of oxidation states (e.g., Fe(II) and Fe(III)) and mineral identities (e.g., Fe-(oxyhydr)oxides) in complex soil samples, which can help to characterize fine-scale redox heterogeneity $[18,66,67]$. Synchrotron X-ray tomography can also be used to measure microscopic structural features in soil to investigate the physical and spatial properties that give rise to redox heterogeneity over short spatiotemporal scales [68]. (4) Microfluidics deals with the design, fabrication, and application of devices/platforms of various material composition (depending on the application) that contain functional and controllable features on the nano- to micro-scale size range [35]. Some microfluidic devices/platforms have been used to study soil-relevant microsites, including mineral transformations and microbial interactions [35,69]. Microfluidics can be used to physically model fine-scale redox heterogeneity in soils, including abiotic and biotic reactions, where devices could also be made that contain micro-electrode arrays for monitoring and/or manipulating fine-scale redox conditions. (5) Agent-based modeling (ABM) allows for the simulation of a complex system of individual entities or agents (e.g., individual microbial cells), including the interactions between them, where each agent can essentially operate according to unique decision-making rules in response to environmental signals. These ABM simulations can be used to study the interactions between different microbes in soil-relevant microsites, including those that have been developed on microfluidic devices/platforms [35]. (6) Molecular dynamics (MD) simulations 
model the behavior of atoms and molecules (e.g., complex organic compounds), including their interactions with each other, surfaces, and aqueous solutions. MD simulations have been increasingly used to describe and explain both inorganic and organic reactions in soil systems and could further help to characterize redox heterogeneity over extremely short spatiotemporal scales [70].

Combinations of some of these techniques can be found in the recent literature cited in this section, however, there needs to be much more development in terms of integrating multiple analyses and diverse expertise to comprehensively study the abiotic and biotic reactions affected by redox heterogeneity in soils. Furthermore, sophisticated high-performance computer methods should be developed in parallel with the use of highpowered analytical techniques to process comprehensive experimental data and to apply the resulting information to numerical models of soils in different environments, which could also potentially benefit earth system models (ESMs) that seek to include fine-scale redox heterogeneity in soil and climate interactions [71]. Multidisciplinary research teams could therefore pair the above techniques in various formats to develop improved multifaceted analyses of redox heterogeneity over short spatiotemporal scales in soil (Figure 4). This combined approach is anticipated to motivate the development of new analytical tools and expand the forefront of environmental research.

\section{Conclusions}

Current research is vastly reshaping the way we interpret redox status when considering a more fine-scale view of heterogeneity in soils, sediments, and aquatic systems. Here, in this paper, a conceptual framework has been specifically developed around redox heterogeneity in soils over short spatiotemporal scales to examine the fundamental entanglement of soil and climate interactions. This conceptual framework can be applied to different abiotic and biotic processes to disentangle these interactions, providing a better understanding of $\mathrm{C}$ and $\mathrm{N}$ transformations that includes greenhouse gas emissions. Importantly, this application depends on greater collaborative efforts to comprehensively investigate redox heterogeneity spanning the domain of microscopic soil interfaces. Some of the most powerful analytical techniques available to study redox heterogeneity have received limited coverage in the environmental sciences, yet are poised to advance emerging areas of research, especially if combined to achieve different research goals. Environmental sustainability on a global scale will continue to be affected by climate-driven redox perturbations in soils that could drastically shift in the immediate future. Agricultural practices, environmental engineering, water-management strategies, and urban development must all address these issues to secure natural resources and to protect human health in the face of climate change. Overall, redox heterogeneity at the level of minerals, microbial cells, organic matter, and the rhizosphere is a fundamental soil property that intricately regulates, yet also allows us to more accurately predict, soil and climate interactions and their sweeping impact on environmental sustainability.

Funding: This research was funded by the Department of Environmental Science and Technology at the University of Maryland, College Park, MD, USA.

Data Availability Statement: Not applicable.

Acknowledgments: The author thanks the reviewers for their valuable feedback, which helped to improve the content of this paper. The author also acknowledges partial funding for open access provided by the UMD Libraries' Open Access Publishing Fund.

Conflicts of Interest: The author declares no conflict of interest.

\section{References}

1. Roden, E.E. Microbial iron-redox cycling in subsurface environments. Biochem. Soc. Trans. 2012, 40, 1249-1256. [CrossRef] [PubMed]

2. Kappler, A.; Bryce, C.; Mansor, M.; Lueder, U.; Byrne, J.M.; Swanner, E.D. An evolving view on biogeochemical cycling of iron. Nat. Rev. Microbiol. 2021, 19, 360-374. [CrossRef] 
3. Keiluweit, M.; Wanzek, T.; Kleber, M.; Nico, P.; Fendorf, S. Anaerobic microsites have an unaccounted role in soil carbon stabilization. Nat. Commun. 2017, 8, 10. [CrossRef]

4. Kappler, A.; Bryce, C. Cryptic biogeochemical cycles: Unravelling hidden redox reactions. Environ. Microbiol. 2017, 19, 842-846. [CrossRef]

5. Sexstone, A.J.; Revsbech, N.P.; Parkin, T.B.; Tiedje, J.M. Direct Measurement of Oxygen Profiles and Denitrification Rates in Soil Aggregates. Soil Sci. Soc. Am. J. 1985, 49, 645-651. [CrossRef]

6. Keiluweit, M.; Gee, K.; Denney, A.; Fendorf, S. Anoxic microsites in upland soils dominantly controlled by clay content. Soil Biol. Biochem. 2018, 118, 42-50. [CrossRef]

7. Lacroix, E.M.; Rossi, R.J.; Bossio, D.; Fendorf, S. Effects of moisture and physical disturbance on pore-scale oxygen content and anaerobic metabolisms in upland soils. Sci. Total Environ. 2021, 780, 11. [CrossRef]

8. Gao, J.J.; Mikutta, R.; Jansen, B.; Guggenberger, G.; Vogel, C.; Kalbitz, K. The multilayer model of soil mineral-organic interfacesA review. J. Plant Nutr. Soil Sci. 2020, 183, 27-41. [CrossRef]

9. Garcia-Robledo, E.; Padilla, C.C.; Aldunate, M.; Stewart, F.J.; Ulloa, O.; Paulmier, A.; Gregori, G.; Revsbech, N.P. Cryptic oxygen cycling in anoxic marine zones. Proc. Natl. Acad. Sci. USA 2017, 114, 8319-8324. [CrossRef] [PubMed]

10. Lalonde, K.; Mucci, A.; Ouellet, A.; Gelinas, Y. Preservation of organic matter in sediments promoted by iron. Nature 2012, 483, 198-200. [CrossRef] [PubMed]

11. Angle, J.C.; Morin, T.H.; Solden, L.M.; Narrowe, A.B.; Smith, G.J.; Borton, M.A.; Rey-Sanchez, C.; Daly, R.A.; Mirfenderesgi, G.; Hoyt, D.W.; et al. Methanogenesis in oxygenated soils is a substantial fraction of wetland methane emissions. Nat. Commun. 2017, 8, 9. [CrossRef]

12. Brouns, K.; Verhoeven, J.T.A.; Hefting, M.M. Short period of oxygenation releases latch on peat decomposition. Sci. Total Environ. 2014, 481, 61-68. [CrossRef] [PubMed]

13. Shoemaker, J.K.; Varner, R.K.; Schrag, D.P. Characterization of subsurface methane production and release over 3 years at a New Hampshire wetland. Geochim. Cosmochim. Acta 2012, 91, 120-139. [CrossRef]

14. Yang, W.H.; McNicol, G.; Teh, Y.A.; Estera-Molina, K.; Wood, T.E.; Silver, W.L. Evaluating the Classical Versus an Emerging Conceptual Model of Peatland Methane Dynamics. Glob. Biogeochem. Cycle 2017, 31, 1435-1453. [CrossRef]

15. Teh, Y.A.; Silver, W.L.; Conrad, M.E. Oxygen effects on methane production and oxidation in humid tropical forest soils. Glob. Chang. Biol. 2005, 11, 1283-1297. [CrossRef]

16. Wilmoth, J.L.; Moran, M.A.; Thompson, A. Transient O-2 pulses direct Fe crystallinity and Fe(III)-reducer gene expression within a soil microbiome. Microbiome 2018, 6, 14. [CrossRef]

17. Rillig, M.C.; Muller, L.A.H.; Lehmann, A. Soil aggregates as massively concurrent evolutionary incubators. ISME J. 2017, 11, 1943-1948. [CrossRef]

18. Tufano, K.J.; Benner, S.G.; Mayer, K.U.; Marcus, M.A.; Nico, P.S.; Fendorf, S. Aggregate-Scale Heterogeneity in Iron (Hydr)oxide Reductive Transformations. Vadose Zone J. 2009, 8, 1004-1012. [CrossRef]

19. Fausser, A.C.; Dusek, J.; Cizkova, H.; Kazda, M. Diurnal dynamics of oxygen and carbon dioxide concentrations in shoots and rhizomes of a perennial in a constructed wetland indicate down-regulation of below ground oxygen consumption. AoB Plants 2016, 8, 15. [CrossRef]

20. Liu, J.J.; Wang, B.; Oldham, C.E.; Hipsey, M.R. Unravelling the metabolism black-box in a dynamic wetland environment using a hybrid model framework: Storm driven changes in oxygen budgets. Sci. Total Environ. 2020, 723, 11. [CrossRef]

21. Borum, J.; Pedersen, O.; Greve, T.M.; Frankovich, T.A.; Zieman, J.C.; Fourqurean, J.W.; Madden, C.J. The potential role of plant oxygen and sulphide dynamics in die-off events of the tropical seagrass, Thalassia testudinum. J. Ecol. 2005, 93, 148-158. [CrossRef]

22. Calabrese, S.; Garcia, A.; Wilmoth, J.L.; Zhang, X.M.; Porporato, A. Critical inundation level for methane emissions from wetlands. Environ. Res. Lett. 2021, 16, 10. [CrossRef]

23. Dhakal, P.; Coyne, M.S.; McNear, D.H.; Wendroth, O.O.; Vandiviere, M.M.; D’Angelo, E.M.; Matocha, C.J. Reactions of nitrite with goethite and surface Fe(II)-goethite complexes. Sci. Total Environ. 2021, 782, 11. [CrossRef] [PubMed]

24. Wang, M.; Hu, R.G.; Ruser, R.; Schmidt, C.; Kappler, A. Role of Chemodenitrification for N2O Emissions from Nitrate Reduction in Rice Paddy Soils. ACS Earth Space Chem. 2020, 4, 122-132. [CrossRef]

25. Mejia, J.; Roden, E.E.; Ginder-Vogel, M. Influence of Oxygen and Nitrate on Fe (Hydr)oxide Mineral Transformation and Soil Microbial Communities during Redox Cycling. Environ. Sci. Technol. 2016, 50, 3580-3588. [CrossRef] [PubMed]

26. Adhikari, D.; Zhao, Q.; Das, K.; Mejia, J.; Huang, R.X.; Wang, X.L.; Poulson, S.R.; Tang, Y.Z.; Roden, E.E.; Yang, Y. Dynamics of ferrihydrite-bound organic carbon during microbial Fe reduction. Geochim. Cosmochim. Acta 2017, 212, 221-233. [CrossRef]

27. Huang, Y.H.; Zhang, T.C. Nitrate Reduction by Surface-Bound Fe(II) on Solid Surfaces at Near-Neutral pH and Ambient Temperature. J. Environ. Eng.-ASCE 2016, 142, 7. [CrossRef]

28. Chen, C.M.; Hall, S.J.; Coward, E.; Thompson, A. Iron-mediated organic matter decomposition in humid soils can counteract protection. Nat. Commun. 2020, 11, 13. [CrossRef]

29. Ettwig, K.F.; Butler, M.K.; Le Paslier, D.; Pelletier, E.; Mangenot, S.; Kuypers, M.M.M.; Schreiber, F.; Dutilh, B.E.; Zedelius, J.; de Beer, D.; et al. Nitrite-driven anaerobic methane oxidation by oxygenic bacteria. Nature 2010, 464, 543-548. [CrossRef]

30. Wilmoth, J.L.; Sexstone, A.J.; McDonald, L.M. Humic Acid Buildup Increases Carbon Dioxide Emissions from Redox-Oscillating Upland Soils while Catalyzing Iron(III) Reduction and Phosphorus Desorption. J. Environ. Qual. 2019, 48, 1614-1621. [CrossRef] 
31. Glasser, N.R.; Saunders, S.H.; Newman, D.K. The Colorful World of Extracellular Electron Shuttles. In Annual Review of Microbiology; Gottesman, S., Ed.; Annual Reviews: Palo Alto, CA, USA, 2017; Volume 71, pp. 731-751.

32. Holmes, D.E.; Shrestha, P.M.; Walker, D.J.F.; Dang, Y.; Nevin, K.P.; Woodard, T.L.; Lovley, D.R. Metatranscriptomic Evidence for Direct Interspecies Electron Transfer between Geobacter and Methanothrix Species in Methanogenic Rice Paddy Soils. Appl. Environ. Microbiol. 2017, 83, 11. [CrossRef]

33. Kato, S.; Hashimoto, K.; Watanabe, K. Microbial interspecies electron transfer via electric currents through conductive minerals. Proc. Natl. Acad. Sci. USA 2012, 109, 10042-10046. [CrossRef] [PubMed]

34. Kato, S.; Igarashi, K. Enhancement of methanogenesis by electric syntrophy with biogenic iron-sulfide minerals. MicrobiologyOpen 2019, 8, 9. [CrossRef] [PubMed]

35. Wilmoth, J.L.; Doak, P.W.; Timm, A.; Halsted, M.; Anderson, J.D.; Ginovart, M.; Prats, C.; Portell, X.; Retterer, S.T.; Fuentes-Cabrera, M. A Microfluidics and Agent-Based Modeling Framework for Investigating Spatial Organization in Bacterial Colonies: The Case of Pseudomonas Aeruginosa and H1-Type VI Secretion Interactions. Front. Microbiol. 2018, 9, 11. [CrossRef] [PubMed]

36. Amstaetter, K.; Borch, T.; Kappler, A. Influence of humic acid imposed changes of ferrihydrite aggregation on microbial Fe(III) reduction. Geochim. Cosmochim. Acta 2012, 85, 326-341. [CrossRef]

37. Kleber, M.; Eusterhues, K.; Keiluweit, M.; Mikutta, C.; Mikutta, R.; Nico, P.S. Mineral-Organic Associations: Formation, Properties, and Relevance in Soil Environments. In Advances in Agronomy; Sparks, D.L., Ed.; Elsevier Academic Press Inc.: San Diego, CA, USA, 2015; Volume 130, pp. 1-140.

38. Sihi, D.; Xu, X.F.; Ortiz, M.S.; O'Connell, C.S.; Silver, W.L.; Lopez-Lloreda, C.; Brenner, J.M.; Quinn, R.K.; Phillips, J.R.; Newman, B.D.; et al. Representing methane emissions from wet tropical forest soils using microbial functional groups constrained by soil diffusivity. Biogeosciences 2021, 18, 1769-1786. [CrossRef]

39. Repeta, D.J.; Ferron, S.; Sosa, O.A.; Johnson, C.G.; Repeta, L.D.; Acker, M.; DeLong, E.F.; Karl, D.M. Marine methane paradox explained by bacterial degradation of dissolved organic matter. Nat. Geosci. 2016, 9, 884-887. [CrossRef]

40. Chari, N.R.; Lin, Y.; Lin, Y.S.; Silver, W.L. Interactive effects of temperature and redox on soil carbon and iron cycling. Soil Biol. Biochem. 2021, 157, 9. [CrossRef]

41. Ginn, B.; Meile, C.; Wilmoth, J.; Tang, Y.Z.; Thompson, A. Rapid Iron Reduction Rates Are Stimulated by High-Amplitude Redox Fluctuations in a Tropical Forest Soil. Environ. Sci. Technol. 2017, 51, 3250-3259. [CrossRef]

42. Martins, P.D.; Hoyt, D.W.; Bansal, S.; Mills, C.T.; Tfaily, M.; Tangen, B.A.; Finocchiaro, R.G.; Johnston, M.D.; McAdams, B.C.; Solensky, M.J.; et al. Abundant carbon substrates drive extremely high sulfate reduction rates and methane fluxes in Prairie Pothole Wetlands. Glob. Chang. Biol. 2017, 23, 3107-3120. [CrossRef]

43. Pangala, S.R.; Moore, S.; Hornibrook, E.R.C.; Gauci, V. Trees are major conduits for methane egress from tropical forested wetlands. New Phytol. 2013, 197, 524-531. [CrossRef] [PubMed]

44. Holmquist, J.R.; Windham-Myers, L.; Bernal, B.; Byrd, K.B.; Crooks, S.; Gonneea, M.E.; Herold, N.; Knox, S.H.; Kroeger, K.D.; McCombs, J.; et al. Uncertainty in United States coastal wetland greenhouse gas inventorying. Environ. Res. Lett. 2018, 13, 15. [CrossRef]

45. Van Beusekom, A.E.; Gould, W.A.; Monmany, A.C.; Khalyani, A.H.; Quinones, M.; Fain, S.J.; Andrade-Nunez, M.J.; Gonzalez, G. Fire weather and likelihood: Characterizing climate space for fire occurrence and extent in Puerto Rico. Clim. Chang. 2018, 146, 117-131. [CrossRef]

46. DeAngelis, K.M.; Silver, W.L.; Thompson, A.W.; Firestone, M.K. Microbial communities acclimate to recurring changes in soil redox potential status. Environ. Microbiol. 2010, 12, 3137-3149. [CrossRef]

47. Dubinsky, E.A.; Silver, W.L.; Firestone, M.K. Tropical forest soil microbial communities couple iron and carbon biogeochemistry. Ecology 2010, 91, 2604-2612. [CrossRef] [PubMed]

48. Liptzin, D.; Silver, W.L.; Detto, M. Temporal Dynamics in Soil Oxygen and Greenhouse Gases in Two Humid Tropical Forests. Ecosystems 2011, 14, 171-182. [CrossRef]

49. Chen, C.M.; Meile, C.; Wilmoth, J.; Barcellos, D.; Thompson, A. Influence of pO(2) on Iron Redox Cycling and Anaerobic Organic Carbon Mineralization in a Humid Tropical Forest Soil. Environ. Sci. Technol. 2018, 52, 7709-7719. [CrossRef]

50. Chen, C.M.; Thompson, A. The influence of native soil organic matter and minerals on ferrous iron oxidation. Geochim. Cosmochim. Acta 2021, 292, 254-270. [CrossRef]

51. Zhao, Q.; Dunham-Cheatham, S.; Adhikari, D.; Chen, C.M.; Patel, A.; Poulson, S.R.; Obrist, D.; Verburg, P.S.J.; Wang, X.L.; Roden, E.R.; et al. Oxidation of soil organic carbon during an anoxic-oxic transition. Geoderma 2020, 377, 9. [CrossRef]

52. Mikutta, C.; Mikutta, R.; Bonneville, S.; Wagner, F.; Voegelin, A.; Christl, I.; Kretzschmar, R. Synthetic coprecipitates of exopolysaccharides and ferrihydrite. Part I: Characterization. Geochim. Cosmochim. Acta 2008, 72, 1111-1127. [CrossRef]

53. Mikutta, R.; Lorenz, D.; Guggenberger, G.; Haumaier, L.; Freund, A. Properties and reactivity of Fe-organic matter associations formed by coprecipitation versus adsorption: Clues from arsenate batch adsorption. Geochim. Cosmochim. Acta 2014, 144, 258-276. [CrossRef]

54. Ajwang'Ondiek, R.; Hayes, D.S.; Kinyua, D.N.; Kitaka, N.; Lautsch, E.; Mutuo, P.; Hein, T. Influence of land-use change and season on soil greenhouse gas emissions from a tropical wetland: A stepwise explorative assessment. Sci. Total Environ. 2021, 787, 12 . 
55. Tully, K.; Sullivan, C.; Weil, R.; Sanchez, P. The State of Soil Degradation in Sub-Saharan Africa: Baselines, Trajectories, and Solutions. Sustainability 2015, 7, 6523-6552. [CrossRef]

56. Padhy, S.R.; Bhattacharyya, P.; Nayak, S.K.; Dash, P.K.; Mohapatra, T. A unique bacterial and archaeal diversity make mangrove a green production system compared to rice in wetland ecology: A metagenomic approach. Sci. Total Environ. 2021, 781, 11. [CrossRef] [PubMed]

57. Wang, R.; Lu, G.N.; Ning, L.; Yuan, L.W.; Li, L.H. Likelihood of compound dry and hot extremes increased with stronger dependence during warm seasons. Atmos. Res. 2021, 260, 10. [CrossRef]

58. Nguyen, T.H.; Sahin, O.; Howes, M. Climate Change Adaptation Influences and Barriers Impacting the Asian Agricultural Industry. Sustainability 2021, 13, 7346. [CrossRef]

59. Arbas, S.M.; Busi, S.B.; Queiros, P.; de Nies, L.; Herold, M.; May, P.; Wilmes, P.; Muller, E.E.L.; Narayanasamy, S. Challenges, Strategies, and Perspectives for Reference-Independent Longitudinal Multi-Omic Microbiome Studies. Front. Genet. 2021, $12,11$.

60. Passarelli, M.K.; Pirkl, A.; Moellers, R.; Grinfeld, D.; Kollmer, F.; Havelund, R.; Newman, C.F.; Marshall, P.S.; Arlinghaus, H.; Alexander, M.R.; et al. The 3D OrbiSIMS-label-free metabolic imaging with subcellular lateral resolution and high mass-resolving power. Nat. Methods 2017, 14, 1175-1183. [CrossRef]

61. Scigelova, M.; Hornshaw, M.; Giannakopulos, A.; Makarov, A. Fourier Transform Mass Spectrometry. Mol. Cell. Proteom. 2011, 10, 19. [CrossRef]

62. Hawkes, J.A.; Dittmar, T.; Patriarca, C.; Tranvik, L.; Bergquist, J. Evaluation of the Orbitrap Mass Spectrometer for the Molecular Fingerprinting Analysis of Natural Dissolved Organic Matter. Anal. Chem. 2016, 88, 7698-7704. [CrossRef]

63. Wang, Y.; Zhang, Z.Y.; Han, L.F.; Sun, K.; Jin, J.; Yang, Y.; Yang, Y.; Hao, Z.N.; Liu, J.F.; Xing, B.S. Preferential molecular fractionation of dissolved organic matter by iron minerals with different oxidation states. Chem. Geol. 2019, 520, 69-76. [CrossRef]

64. Zhang, J.T.; Brown, J.; Scurr, D.J.; Bullen, A.; MacLellan-Gibson, K.; Williams, P.; Alexander, M.R.; Hardie, K.R.; Gilmore, I.S.; Rakowska, P.D. Cryo-OrbiSIMS for 3D Molecular Imaging of a Bacterial Biofilm in Its Native State. Anal. Chem. 2020, 92, 9008-9015. [CrossRef]

65. Steffens, M.; Rogge, D.M.; Mueller, C.W.; Hoschen, C.; Lugmeier, J.; Kolbl, A.; Kogel-Knabner, I. Identification of Distinct Functional Microstructural Domains Controlling C Storage in Soil. Environ. Sci. Technol. 2017, 51, 12182-12189. [CrossRef] [PubMed]

66. Joe-Wong, C.; Schlesinger, D.R.; Chow, A.T.; Myneni, S.C.B. Sea level rise produces abundant organobromines in salt-affected coastal wetlands. Geochem. Perspect. Lett. 2019, 10, 31-35. [CrossRef]

67. Lombi, E.; Susini, J. Synchrotron-based techniques for plant and soil science: Opportunities, challenges and future perspectives. Plant. Soil 2009, 320, 1-35. [CrossRef]

68. Wang, W.P.; Zhang, Y.F.; Li, H. Quantification of soil structure via synchrotron X-ray tomography after 22 years of fertilization. Eur. J. Soil Sci. 2021, 72, 2115-2127. [CrossRef]

69. Yang, J.Q.; Zhang, X.N.; Bourg, I.C.; Stone, H.A. 4D imaging reveals mechanisms of clay-carbon protection and release. Nat. Commun. 2021, 12, 8 .

70. Willemsen, J.A.R.; Bourg, I.C. Molecular dynamics simulation of the adsorption of per- and polyfluoroalkyl substances (PFASs) on smectite clay. J. Colloid Interface Sci. 2021, 585, 337-346. [CrossRef] [PubMed]

71. Dunne, J.P.; Horowitz, L.W.; Adcroft, A.J.; Ginoux, P.; Held, I.M.; John, J.G.; Krasting, J.P.; Malyshev, S.; Naik, V.; Paulot, F.; et al. The GFDL Earth System Model Version 4.1 (GFDL-ESM 4.1): Overall Coupled Model Description and Simulation Characteristics. J. Adv. Model. Earth Syst. 2020, 12, 56. [CrossRef] 